\title{
Influence of tibial slope asymmetry on femoral rotation in patients with lateral patellar instability
}

\author{
Raj R. Thakrar $\cdot$ Martyn Snow
}

Received: 30 September 2013/Accepted: 28 October 2013/Published online: 12 November 2013

(C) Springer-Verlag Berlin Heidelberg 2013

\section{Dear Sir,}

We read the above article by Balcarek et al. with great interest and acknowledge an under representation in literature of this complex and challenging topic.

We wish to raise a few points on the methodology and results presented by the authors.

In this study, the authors describe the use of a 2D model for the measurement of medial and lateral tibial slope angles. It is recognised in literature that in the normal knee, the knee joint rotational angle (external rotation of proximal tibia relative to the distal femur) may be up to $9.2^{\circ} \pm 5.6^{\circ}$ [3]. A study in patients with patella instability by Seitlinger et al. [1] quoted values of $5.9^{\circ} \pm 4.7^{\circ}$. Due to this rotation, the tibia will be viewed obliquely when using a 2D CT image. Whilst the authors do try to obtain the widest section in an attempt to obtain a true lateral, in reality this is likely to be a diagonal. This rotation will affect the values measured for posterior slope and subsequently affect the outcome of their study. This effect of external rotation on the tibial slope has been highlighted in a recent study by Tsukeoka et al. [2]. They determined that during a TKR, a tibial cutting block mal-alignment of $20^{\circ}$ of external rotation can produce varus mal-alignment of $2.4^{\circ}$ and $3.5^{\circ}$ with a $7^{\circ}$ and a $10^{\circ}$ sloped cutting jig,

\section{R. R. Thakrar $(\bowtie)$}

Department of Arthroscopy, SpR Trauma and Orthopaedics, The Royal Orthopaedic Hospital NHS Trust, Bristol Road South, Birmingham B31 2AP, UK

e-mail: r.r.thakrar@gmail.com

\section{Snow}

Department of Arthroscopy, Consultant Orthopaedic Surgeon, The Royal Orthopaedic Hospital NHS Trust, Bristol Road South, Birmingham B31 2AP, UK

e-mail: snowmartyn@gmail.com respectively. This study demonstrates effectively that external rotation will reduce the posterior slope and create a deformity in another plane.

Furthermore, it would be of interest to correlate the authors findings with the clinical significance of an increase in femoral rotation as a consequence of variation in the posterior slope. The mean difference in the rotation presented between the two extreme groups in this study is a couple of degrees with a large standard deviation. Bearing in mind the aforementioned studies and that the knee joint rotation angle in the normal knee can vary between $-2^{\circ}$ and $20.4^{\circ}$, it may be presumed unlikely that a $2^{\circ}$ increase in femoral rotation would make a significant difference in the clinical setting.

Finally, clarification is needed by the authors on their concluding statement regarding the effects of an increase in medial slope on anteriorising the tibiofemoral contact point. Our understanding is that an increase in the medial slope would posteriorise the tibiofemoral contact point, increasing internal rotation of the femur. This in turn would be more likely to augment the effects of intra- and extraarticular-rotational deformities.

\section{References}

1. Seitlinger G, Scheurecker G, Högler R, Labey L, Innocenti B, Hofmann S (2012) Tibial tubercle-posterior cruciate ligament distance: a new measurement to define the position of the tibial tubercle in patients with patellar dislocation. Am J Sports Med 40:1119-1125

2. Tsukeoka T, Tsuneizumi Y, Lee TH (2013) The effect of the posterior slope of the tibial plateau osteotomy with a rotational error on tibial component malalignment in total knee replacement. Bone Joint J 95-B:1201-1203

3. Yagi $T$ (1994) Tibial torsion in patients with medial-type osteoarthrotic knees. Clin Orthop Relat Res 302:52-56 